OPEN ACCESS

Edited by:

Jon-Chao Hong,

National Taiwan Normal University,

Taiwan

Reviewed by:

Ya-Ling Wang,

National Taiwan Normal University,

Taiwan

Francesca Giovanna Maria

Gastaldi,

University of Turin, Italy

Min-Hsien Lee,

National Taiwan Normal University,

Taiwan

${ }^{*}$ Correspondence:

Xuesong Zhai

xszhai@zju.edu.cn

Specialty section:

This article was submitted to

Educational Psychology,

a section of the journal

Frontiers in Psychology

Received: 07 January 2021 Accepted: 07 May 2021

Published: 29 July 2021

Citation:

Zheyu L, Weijin C, Jihui Z, Yuan W, Ghani $U$ and Zhai X (2021)

Investigating the Influence of Tacit Knowledge Transformation Approach

on Students' Learning Ability.

Front. Psychol. 12:647729.

doi: 10.3389/fpsyg.2021.647729

\section{Investigating the Influence of Tacit Knowledge Transformation Approach on Students' Learning Ability}

\author{
Liu Zheyu ${ }^{1}$, Cui Weijin' ${ }^{1}$ Zhou Jihui' ${ }^{1}$ Wang Yuan ${ }^{1}$, Usman Ghani ${ }^{2,3}$ and Xuesong Zhai2* \\ ${ }^{1}$ Faculty of Education, Tianjin Normal University, Tianjin, China, ${ }^{2}$ College of Education, Zhejiang University, Hangzhou, China, \\ ${ }^{3}$ Department of Business Administration, Iqra University, Karachi, Pakistan
}

Tacit knowledge is an essential foundation for developing students' learning ability, especially in understanding and solving problems. However, the transforming of tacit knowledge confront a big challenge during the outbreak of Corona Virus Disease 2019 (COVID-19), because most teaching and learning activities were conducted in online context, which impair a face-to-face interaction. To explore the effect of tacit knowledge on students' learning ability in the online learning environments, the current study based on SECl model (The Socialization, Externalization, Combination, and Internalization) proposed to design the tacit knowledge transformation teaching approach. To assess the effectiveness of this approach, 60 elementary school students were recruited in the quasi-experiment. The results of retention test and transfer test showed that the experimental group, using the tacit knowledge transformation teaching approach, has significant improvement on learning ability than the control group. The current research theoretically provide a teaching strategy on tactic knowledge, and practically helps teachers to organize instructional activities, thereby, advocating the appropriate use of social media.

\section{Keywords: tacit knowledge, transformation model, student well-being, online learning, social media}

\section{INTRODUCTION}

During the spread of Corona Virus Disease 2019 (COVID-19) globally, physical classes had to be transferred to online settings, which brought dramatic challenges to the traditional curriculum. Educators are getting adapted to online instruction (Chen et al., 2020). However, the online teaching setting is still facing many challenges, which may negatively affect the quality of learning and students' well-being (Zandvliet et al., 2019). The reason may due to that online learning probably help enhance the comprehension and memorization of explicit knowledge, neglecting the tacit knowledge used to solve problems, and restricts teacher-student interaction.

Tacit knowledge considerably influences students' ability to understand and solve problems in learning (Chamidy et al., 2020). Tacit knowledge was regarded playing a fundamental role in triggering problem discovery, and further facilitate contextual understanding (Collins, 2001). For 
example, the situation may commonly happen: students remembered how teachers solve problems but fail to figure them out in a new context. Ignoring the problem of transforming tacit knowledge leads students to be confused in problem solving (Chamidy et al., 2020), and may bring anxiety to students (Larcombe et al., 2013). Therefore, it is urgent to explore an implementable approach capable of transforming tacit knowledge effectively in online settings.

The Socialization, Externalization, Combination, and Internalization (SECI) model was defined as an organization which creates knowledge through the interactions between explicit knowledge and tacit knowledge. As a knowledge transformation approach proposed by Nonaka and Takeuchi (1995), the SECI approach has been widely accepted in the field of education. It illustrates the learning process at the level of knowledge transfer and transformation to enable students to explicitly and intentionally construct, update, and apply knowledge (Xue et al., 2020). The current study, based on SECI, proposed to construct a tacit knowledge transformation approach in online learning, and evaluate how the approach influences learners' internalization of their tacit knowledge.

\section{LITERATURE REVIEW}

\section{Learning Dilemmas Under the Epidemic}

The outbreak of COVID-19 had serious implications on education worldwide. In response to the epidemic, schools opted to restore normalcy by employing conferencing software to deliver online teaching on a large scale (Adnan and Anwar, 2020). Despite these conference tools have improved the relevant functions to meet the needs of online teaching, some existing problems are still exposed. Owing to technical limitations, online education is generally instructor-centered on lecturing with a lack of interaction between teachers and students (Chen et al., 2020). As a result, it leads not only to deficiency of translation and application of knowledge in problem solving, but also to lack of interpersonal communication and interaction in the instructional system (Adnan and Anwar, 2020).

\section{Tacit Knowledge}

Knowledge is typically classified into tacit knowledge and explicit knowledge (Polanyi, 1962). Different from the explicit knowledge, tacit knowledge has been defined as personal knowledge that is difficult to formalize and describe through language (Tamzini, 2015). Tacit knowledge is more fundamental than explicit knowledge. It was found that students with high tacit knowledge gained higher academic achievement than those with low tacit knowledge (Chamidy et al., 2020). Besides, tacit knowledge as an experience and skill promote student understanding and solving problems (Ibidunni et al., 2018). Prior research has substantiated that the effective transformation of tacit knowledge may improve students' ability to comprehend and solve problems, thereby enhancing their sustainable wellbeing (Tan et al., 2019).

\section{Tacit Knowledge Transformation Approach}

The SECI model consists of four knowledge transformation modes: SECI (Nonaka et al., 2000). Students concentrate solely on the explicit knowledge in the book or the teacher's language, making it difficult for them to develop the necessary associations, imaginations, and deductive thinking. Through the construction of a tacit knowledge transformation approach, researchers can design student-student interactions that promote a positive classroom climate (Nurmi and Kiuru, 2015). It can also guide tacit knowledge transformation to achieve a higher level of students' problem understanding and solving (Chamidy et al., 2020).

The implicit nature of tacit knowledge makes it difficult for learners to access it directly through explicit symbols, which compromises the activation, transformation, and construction of tacit knowledge in the classroom (Ambrosini and Bowman, 2001). The successful experience of tacit knowledge transformation in the field of management is based on tacit knowledge transformation approach (Sasaki, 2017). Existing research on tacit knowledge transformation in online learning emphasizes the use of a specific technique or strategy (Silby and Watts, 2015). Hence, the design and development of tacit knowledge transformation approaches in online environment settings require further research.

\section{METHOD}

\section{Designing}

The present study builds a tacit knowledge transformation approach for online learning (see Figure 1) based on the SECI model. The tacit knowledge transformation approach in online classroom focuses on the spiral from tacit knowledge to explicit knowledge fragments, combinatorial explicit knowledge, and internalization of tacit knowledge. The spiral process leads to the generation of higher-order ways of thinking. To achieve this, originating, interacting, cyber, and exercising fields were constructed with technological support (Nonaka et al., 2000), thus aiding the transformation from socialization (organization of socialization, extraction of tacit knowledge, and feelings perceptions and empathy) to externalization (organization of externalization and tacit knowledge explicitly), to combination (contrast, synthesis and deduction and, summary and convergence), and to internalization (implementation and, evaluation and restructuring). The approach assists in creating the context by supporting the "field" (i.e., originating field, interacting field, and cyber field and exercising field) environment with information technology.

The originating field is a place of tacit knowledge exchange among the learners, providing an original basis for the learner to share their experiences and helping them to socialize with each others. The transformation of tacit knowledge at this stage can be implemented through observational learning, activity-based learning, and symbolic learning. For example, teachers may set up scenario-based case observation activities in the virtual classroom 


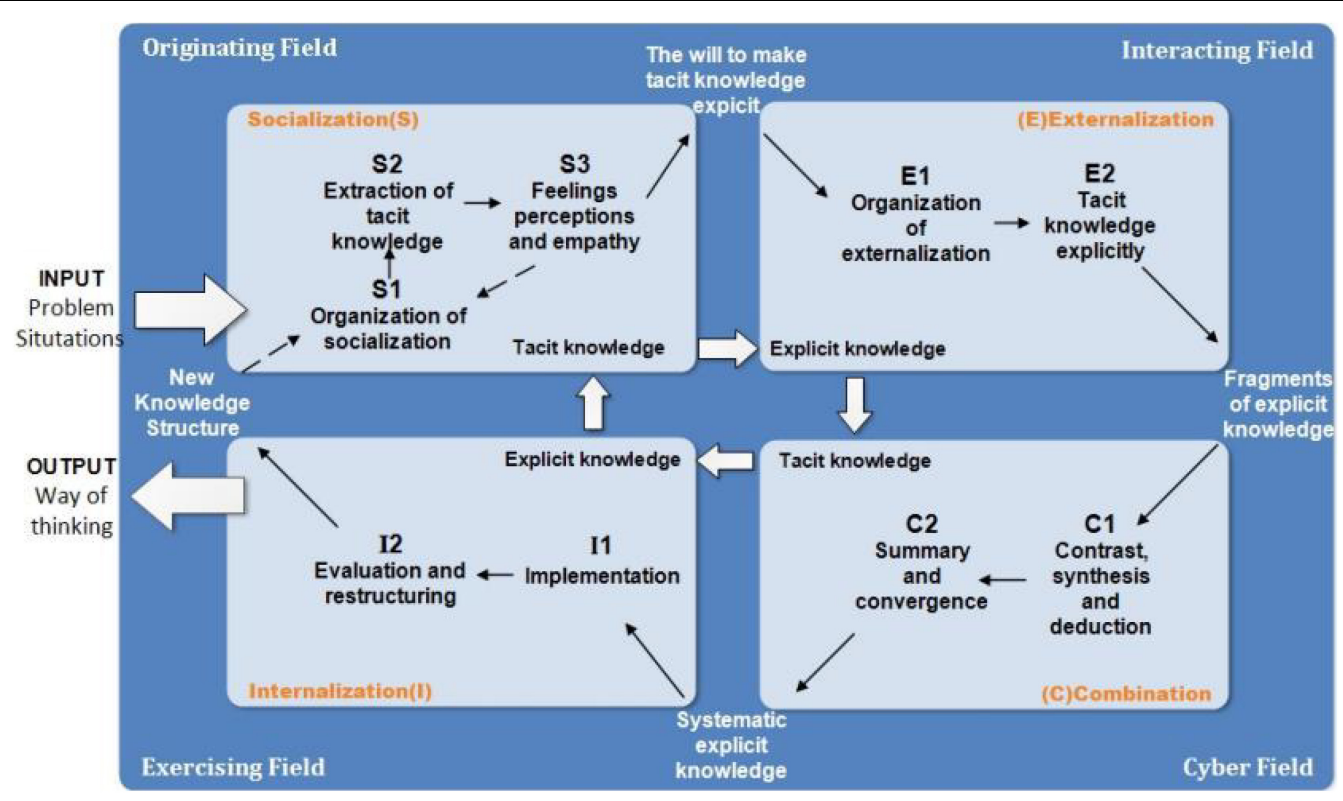

FIGURE 1 | The approach of tacit knowledge transformation in online classroom.

online or narrative activities among students. Social Networking Services (SNS) platforms (Jeong et al., 2015), online communities (Kassem et al., 2015), and social media interactions (Chatti et al., 2007) can effectively assist in the construction of the original field and the convergence of tacit knowledge.

The interacting field is a place where knowledge activities took place, providing contextual support for an open presentation and deep communication among learners. In the externalization stage, learners collect and organize materials, and teachers guide students to articulate and communicate their tacit knowledge with others. Learners share their tacit knowledge through metaphors, simulations, or diagrams, transforming it into explicit knowledge fragments that could spread on the social media. Online groups (Thomas and Thorpe, 2019) and multi-device platforms (Little and Knihova, 2014) can support learners' knowledge externalization in addition to media interaction.

The cyber field is a place where the pieces of explicit knowledge generated in the previous stage, are combined and processed, and new knowledge is generated. Knowledge is systematized in the learning community through comparison, synthesis, deduction, and reasoning. In the combination stage, collaboration between learning committees play an important role. They collaborate to summarize the fragmented explicit knowledge to form the systematic explicit knowledge in the learning community. The construction of system fields can be effectively supported by cognitive map (Rodhain, 1999) and mind map (Leckie et al., 2010), which help in the combination of explicit knowledge.

The exercising field is a place where new knowledge is applied, evaluated, and reflected on in practical exercises. In the internalization stage, the explicit knowledge of the community is internalized into the conscious behavior of the students through practice. After the practice, the students will assess and reconstruct their tacit knowledge structures and thinking patterns. Educational games (Noemí and Máximo, 2014) and virtual reality (Smith et al., 2012) effectively create real-life situations and help learners to learn by practice.

\section{Participants}

The participants were recruited from an elementary school in Eastern China. We collected valid data from 60 sixthgrade students, of which 32 were male and 28 were female, 31 students age was ranged from 10 to 12 years, while 29 students age was ranged from 12 to 14 years, 35 students belong to urban area and 25 students belong to rural area (see Table 1). The participants were randomly divided into two groups (control group and experimental group) with 76 subjects in each group. A gift was offered to all the respondents for their participation.

\section{Procedure}

The pre-test of the control and experimental classes were two math test scores (midterm test and September joint test). Each participant received an instruction sheet and a consent form before the experiment.

TABLE 1 | Demographic variables $(N=60)$.

\begin{tabular}{lccc}
\hline Variables & Category & N & Percentage (\%) \\
\hline Gender & Male & 32 & 53.33 \\
\multirow{2}{*}{ Age } & Female & 28 & 46.67 \\
& $10-12$ & 31 & 51.67 \\
Residence & $12-14$ & 29 & 48.33 \\
& Urban & 35 & 58.33 \\
& Rural & 25 & 61.67
\end{tabular}


During the experiment, the online application DingTalk is used as a teaching platform. First, the teacher completes the instructional design of the "Understanding the Circle" on his/her own and teaches it in the control group. After completing the lesson, the instructors ask students to fill in the posttest which is a learning outcome test. The test of learning outcomes is a standardized paper that contained a retention test and a transfer test. Retention-transfer test is widely used both domestically and internationally (Cheng and Beal, 2020; Knoop-van Campen et al., 2020). Secondly, the teacher teaches in the experimental class based on the teaching design of "Understanding the Circle" developed by the SECI model, and teaches it in the experimental group. After completing the lesson, we ask students to fill out the learning outcome tests. Finally, took back the test questions for grading. Concrete teaching details and items of the learning outcome test are available in the supplementary files.

\section{RESULTS}

The SPSS 21.0 was employed in analyzing the collecting data. The descriptive results of pre-test and post-test scores for two groups are shown in Table 2 . To check the normality of the data, Kline's (2015) criteria was used, which states that the data are normally distributed when the skewness and kurtosis are under $|3|$ and $\mid$ 10| respectively. The final results for skewness ( -1.062 to 1.516$)$ and kurtosis ( -1.132 to 3.854$)$ values indicate that both the pretest, retention test, and transfer test were normally distributed.

Therefore, the ANCOVA test was employed to analyze the difference in retention and transfer performance between the two groups. Regarding the retention of knowledge (see Table 3), there was significant difference $(F=311.41, p<0.0001)$ between the two groups, showing that the SECI model was able to improve student retention performance. The analysis of the knowledge transfer test (see Table 4) showed a significant difference $(F=323,13, p<0.0001)$ between two groups, which indicated that students' knowledge transfer was enhanced with the utilization of the SECI model.

\section{DISCUSSION}

The current study investigates the underlying mechanism of transformation of tacit knowledge to promote students' learning ability in understanding and solving problems. An

TABLE 2 | Descriptive statistical data of the two groups' pretest and posttest.

\begin{tabular}{lcccc}
\hline Test & Group & N & Mean & SD \\
\hline Pretest & Experimental group & 30 & 83.70 & 8.53 \\
& Control group & 30 & 85.40 & 9.89 \\
Posttest for the retention of & Experimental group & 30 & 89.38 & 14.42 \\
knowledge & & & & \\
& Control group & 30 & 67.08 & 18.42 \\
Posttest for the knowledge transfer & Experimental group & 30 & 73.33 & 20.69 \\
& Control group & 30 & 37.08 & 18.12
\end{tabular}

approach of tacit knowledge transformation for online learning is designed in this study.

Before the approach was implemented, the teacher reported some reflections on tacit knowledge transformation:

\begin{abstract}
Although I pay more attention to the students' understanding, considering the low motivation of the students and the lack of effective means of transformation, when doing some exercises, even if it has some implicit context, we often ignore it, that is, to directly practice their calculations. I think it would be helpful if some implementable online tacit knowledge transformation approach could be provided to teachers.
\end{abstract}

In this excerpt, the teachers reflectively analyzed their ideas in the transformation of tacit knowledge. They argued that the dilemma of transforming tacit knowledge in online environment is widespread, and the central problem is the lack of effective instructional means. This offers useful insights, as teachers recognize that effective approaches of tacit knowledge transformation are essential. Likewise, Songkram and Chootongchai's (2020) study indicates that using the SECI model to share knowledge in the classroom allows students to develop their creative potential. Therefore, this study, further examined the performance of students' learning with and without the tacit knowledge transformation approach.

After the experiment, the results confirmed that the tacit knowledge transformation approach with four stages (socialization, internalization, externalization, and combination) were successful, indicating that the tacit knowledge transformation approach promoted students' cognitive development at all stages. Existing research has identified socialization (transformation of tacit knowledge to other forms of tacit knowledge) and externalization (transformation of tacit knowledge to explicit knowledge) as important factors influencing students' learning outcomes and learning experience (Ibidunni et al., 2020). Without significant differences between students' levels, there were significant differences in both retention and transfer scores of students after the experiment. Among this, transfer ability showed the most significant difference which indicates that the transformation approach of tacit knowledge can effectively contribute to students' ability to understand and solve problems. Through the use of this approach, the teacher made the following observations:

TABLE 3 | ANCOVA of the posttest for the retention of knowledge.

\begin{tabular}{|c|c|c|c|c|c|c|}
\hline Group & $N$ & Mean & SD & Adjusted mean & $\boldsymbol{F}$ & $\eta 2$ \\
\hline Experimental group & 30 & 89.37 & 14.41 & 90.81 & $311.41^{\star \star \star}$ & 0.85 \\
\hline Control group & 30 & 67.08 & 18.77 & 65.65 & & \\
\hline
\end{tabular}

TABLE 4 | ANCOVA of the posttest for the knowledge transfer.

\begin{tabular}{lcccccc}
\hline Group & N & Mean & SD & Adjusted mean & $\boldsymbol{F}$ & \multicolumn{1}{c}{ ? } \\
\hline Experimental group & 30 & 73.33 & 20.69 & 74.94 & $323.13^{\star \star \star}$ & 0.85 \\
Control group & 30 & 37.08 & 18.12 & 35.47 & & \\
\hline
\end{tabular}

${ }^{* * *} p<0.001$. 
I think this approach can be very well applied to the online classroom. I feel that I was able to use this approach very well and my students' thinking was able to be developed through it. The core idea of mathematics is to develop students' thinking level, so I will change my teaching method in the future.

I have noticed that students that used the tacit knowledge transformation approach can transform their tacit knowledge into mind maps and apply it consciously in their practice. Each student communicates what they have learned in their group, completing the mind map and then presenting it to the whole class. This process helped them to improve their problem solving skills.

In these narratives, teachers demonstrated an encouraging view about tacit knowledge transformation approach that could successfully assist students in understanding and solving problems. The transformation of tacit knowledge is carried out through instructional activities. There are three types of instructional activities of interactions in class: between teacher and student, between student and student, and by students themselves. By using the tacit knowledge transformation approach, teachers were able to solve the confusion of students whose tacit knowledge could not be transformed and paved the cognitive level building blocks to enhance students' well-being.

\section{LIMITATIONS AND FUTURE STUDY}

The current study is not lacking limitations and should be acknowledged by future research. First, the number of participants were small, which may limit the generalizability of the results. Future research should investigate whether the approach for transformation of tacit knowledge have the same impact on larger number of students, so that our findings could be validated further. Second, this study only interviewed teachers and did not collect feedback from students. Future research should could incorporate students' emotional experiences for further analysis, such as interviews, FaceReader. Third, this study

\section{REFERENCES}

Adnan, M., and Anwar, K. (2020). Online Learning amid the COVID-19 Pandemic: Students' Perspectives. Online Submiss. 2, 45-51. doi: 10.33902/jpsp. 2020261309

Ambrosini, V., and Bowman, C. (2001). Tacit Knowledge: Some Suggestions for Operationalization. J. Manage. Stud. 38, 811-829. doi: 10.1111/1467-6486. 00260

Chamidy, T., Degeng, I., and Ulfa, S. (2020). The Effect of Problem Based Learning and Tacit Knowledge on Problem-Solving Skills of Students in Computer Network Practice Course. J. Educ. Gift. Young Sci. 8, 691-700. doi: 10.17478/ jegys.650400

Chatti, M. A., Klamma, R., Jarke, M., and Naeve, A. (2007). "The web 2.0 driven SECI model based learning process," in Advanced Learning Technologies, Proceedings of the Seventh IEEE International Conference, (Istanbul: ICALT).

Chen, T., Peng, L., Jing, B., Wu, C., Yang, J., and Cong, G. (2020). The Impact of the COVID-19 Pandemic on User Experience with Online Education Platforms in China. Sustainability 12:7329. doi: 10.3390/su12187329

Cheng, L., and Beal, C. R. (2020). Effects of student-generated drawing and imagination on science text reading in a computer-based learning environment. Educat. Technol. Res. Dev. 68, 225-247. doi: 10.1007/s11423-019-09684-1 only included a limited number of teachers in the interviews, thus their comments may not be representative. We suggest that future research could interview more teachers and conduct a discourse analysis of their comments.

\section{DATA AVAILABILITY STATEMENT}

The raw data supporting the conclusions of this article will be made available by the authors, without undue reservation.

\section{ETHICS STATEMENT}

The studies involving human participants were reviewed and approved by the Ethics Committee of Tianjin Normal University, China. Written informed consent to participate in this study was provided by the participants' legal guardian/next of kin.

\section{AUTHOR CONTRIBUTIONS}

LZ and XZ: conceptualization. CW: formal analysis and writingoriginal draft preparation. ZJ and WY: investigation. LZ, UG, and XZ: writing-review. All authors have read and agreed to the published version of the manuscript.

\section{FUNDING}

The research was supported by the National Natural Science Foundation of China (NSFC): The Multimodel Study on Mechanism for Self-regulation in Deep Learning, 61907032, the Youth Foundation of Humanities and Social Sciences Project of the Ministry of Education in China (Grant ID: 20YJC880118), and the 2021 Fundamental Research Funds for the Central Universities.

Collins, H. M. (2001). Tacit Knowledge, Trust and the Q of Sapphire. Soc. Stud. Sci. 31, 71-85. doi: 10.1177/030631201031001004

Ibidunni, A. S., Ibidunni, O. M., Akinbola, O. A., Olokundun, M. A., and Ogunnaike, O. O. (2020). Conceptualizing a teacher-student knowledge exchange perspective: exploring the tripartite relationships between SECI theory, LMX theory and HEIs' students' preparedness for the workplace. Higher Educat. Skills Work Based Learn. 11, 330-348.

Ibidunni, A. S., Ibidunni, O. M., Oke, A. O., Ayeni, A. W., and Olokundun, A. M. (2018). Examining the Relationship Between Tacit Knowledge Of Individuals And Customer Satisfaction. Acad. Entrep. J. 24:S0144686X16001136. doi: 10. 1017/0144686X16001136

Jeong, H., Hong, B. H., and Park, J. H. (2015). User tailored cloud-learning system using SNS and learning resources. Multimed. Tools Appl. 74, 5073-5084. doi: 10.1007/s11042-013-1717-0

Kassem, S., Hammami, S., and Alhousary, T. (2015). Applying seci model to encourage knowledge creation in elearning environment. Ind. J. Econ. Res. 12, 1601-1611.

Kline, R. B. (2015). Principles and practice of structural equation modeling. New York, NY: Guilford publications.

Knoop-van Campen, C. A., Segers, E., and Verhoeven, L. (2020). Effects of audio support on multimedia learning processes and outcomes in students with dyslexia. Comput. Educat. 150:103858. doi: 10.1016/j.compedu.2020.103858 
Larcombe, W., Tumbaga, L., Malkin, I., and Nicholson, P. (2013). Does an improved experience of law school protect students against depression, anxiety and stress: an empirical study of wellbeing and the law school experience of LLB and JD students. Sydney Law Rev. 35:407.

Leckie, G., Given, L., and Buschman, J. (eds) (2010). Critical theory for library and information science: exploring the social from across the discipline. Santa Barbara, CA: Libraries Unlimited.

Little, B., and Knihova, L. (2014). Modern trends in learning architecture. Ind. Commer. Train. 46, 34-38. doi: 10.1108/ict-07-2013-0046

Noemí, P. M., and Máximo, S. H. (2014). Educational games for learning. Univers. J. Educ. Res. 2, 230-238.

Nonaka, I., and Takeuchi, H. (1995). The knowledge-creating company: How Japanese companies create the dynamics of innovation. Oxford: Oxford university press.

Nonaka, I., Toyama, R., and Konno, N. (2000). Seci, ba and leadership: a unified model of dynamic knowledge creation. Long Range Plan. 33, 5-34. doi: 10.1016/ S0024-6301(99)00115-6

Nurmi, J. E., and Kiuru, N. (2015). Students' evocative impact on teacher instruction and teacher-child relationships: Theoretical background and an overview of previous research. Int. J. Behav. Dev. 39, 445-457. doi: 10.1177/ 0165025415592514

Polanyi, M. (1962). Personal Knowledge. Chicago: The University of Chicago Press.

Rodhain, F. (1999). "Tacit to explicit: transforming knowledge through cognitive mapping-experiment," in Proceeding of the ACM SIGCPR Conference on Computer Personnel Research, (Los Angeles: ACM).

Sasaki, Y. (2017). "A note on systems intelligence in knowledge management". Learn. Organ. 24, 236-244. doi: 10.1108/TLO-09-2016-0062

Silby, A., and Watts, M. (2015). Making the tacit explicit: children's strategies for classroom writing. Br. Educ. Res. J. 41, 801-819. doi: 10.1002/berj.3176

Smith, R., Gray, J., Raymond, J., Catling-Paull, C., and Homer, C. S. (2012). Simulated learning activities: improving midwifery students' understanding of reflective practice. Clin. Simul. Nurs. 8, 451-457e. doi: 10.1016/j.ecns.2011.04. 007

Songkram, N., and Chootongchai, S. (2020). Effects of pedagogy and information technology utilization on innovation creation by seci model. Education and Information Technologies 25, 4297-4315. doi: 10.1007/s10639-020-10150-2

Tamzini, K. (2015). "Strategic Tacit Knowledge-Based Competitiveness," in Knowledge Management for Competitive Advantage During Economic Crisis, eds
P. Ordoñez de Pablos, L. Turró, R. Tennyson, and J. Zhao (Hershey, PA: IGI Global), 140-163. doi: 10.4018/978-1-4666-6457-9.ch009

Tan, C. S., Tan, S. A., Mohd Hashim, I. H., Lee, M. N., Ong, A. W. H., and Yaacob, S. N. B. (2019). Problem-Solving Ability and Stress Mediate the Relationship Between Creativity and Happiness. Creativ. Res. J. 31, 15-25. doi: 10.1080/ 10400419.2019.1568155

Thomas, G., and Thorpe, S. (2019). Enhancing the facilitation of online groups in higher education: a review of the literature on face-to-face and online groupfacilitation. Interact. Learn. Environ. 27, 62-71. doi: 10.1080/10494820.2018. 1451897

Xue, L., Rienties, B., Van Petegem, W., and Van Wieringen, A. (2020). Learning relations of knowledge transfer (KT) and knowledge integration (KI) of doctoral students during online interdisciplinary training: an exploratory study.High. Educ. Res. Dev. 39, 1290-1307. doi: 10.1080/07294360.2020. 1712679

Zandvliet, D. B., Stanton, A., and Dhaliwal, R. (2019). Design and Validation of a Tool to Measure Associations between the Learning Environment and Student Well-Being: The Healthy Environments and Learning Practices Survey (HELPS). Innov. High Educ. 44, 283-297. doi: 10.1007/s10755-0199462-6

Conflict of Interest: The authors declare that the research was conducted in the absence of any commercial or financial relationships that could be construed as a potential conflict of interest.

Publisher's Note: All claims expressed in this article are solely those of the authors and do not necessarily represent those of their affiliated organizations, or those of the publisher, the editors and the reviewers. Any product that may be evaluated in this article, or claim that may be made by its manufacturer, is not guaranteed or endorsed by the publisher.

Copyright (c) 2021 Zheyu, Weijin, Jihui, Yuan, Ghani and Zhai. This is an openaccess article distributed under the terms of the Creative Commons Attribution License (CC BY). The use, distribution or reproduction in other forums is permitted, provided the original author(s) and the copyright owner(s) are credited and that the original publication in this journal is cited, in accordance with accepted academic practice. No use, distribution or reproduction is permitted which does not comply with these terms. 